\title{
Editorial
}

\section{Individual Susceptibility to Occupational Hazard}

A term "Individual Susceptibility" in this special issue means the vulnerability of individual to be harmed by an occupational hazard, which is related to a variety of factors. As the well-known text book "Casarett and Doull's Toxicology: The Basic Science of Poisons"1) says, these factors include genetic traits, sex and age, preexisting diseases, behavioral traits (most importantly, smoking), coexisting exposures, medications, vitamins, and protective measures. Ecogenetic studies in toxicology have been focused on inherited variation in susceptibility to external exposures such as pharmaceuticals, pesticides, inhaled pollutants, food and food additives, sensory stimuli, allergic and sensitizing agents, and infectious agents ${ }^{1}$. In the early years, investigations on individual variation in response to chemicals were made especially on genetic polymorphisms in enzymes involved in xenobiotic metabolism ${ }^{2}$.

When PubMed is searched for the susceptibility, we can found a large number of articles on individual variability in relation to the effects of occupational exposures. For example, Godderis et al. ${ }^{3)}$ suggested that the polymorphism in glutathione S- transferase affects neurotoxicity of solvents, i.e. GSTT1 is protective against sleep and sensorimotor complaints, whereas GSTM1 decreases sustained attention and short-term memory problems in relation to solvent exposure; they also indicated that individuals possessing DRD2-141Cdel variant in dopamine D receptor experienced more visuomotor problems. A metaanalysis on delta-aminolevulinic acid dehydratase (ALAD) genotypes and blood lead levels indicated that ALAD genotypes may affect the susceptibility of workers to lead ${ }^{4}$. For workers exposed to asbestos, it is suggested that GSTP1*105Val allele and low EPHX1 activity genotype (glutathione S-transferases and microsomal epoxide hydrolase, respectively) are protective ${ }^{5)}$. Yucesoy et al. ${ }^{6)}$ conducted a case-control study to test the hypothesis that the polymorphisms within genes involved in inflammatory and fibrotic processes modulate the risk of progressive massive fibrosis among underground coal miners, and observed that the polygenotype of VEGF +405/ICAM-1 +241/IL-6 -174 (C-A-G) conferred an increased risk for PMF (VEGF = vascular endothelial growth factor and ICAM = epidermal growth factor intercellular cell adhesion molecule). The susceptibility, of course, must be concern in non-occupational exposures, as reported by Liao YT et al. ${ }^{7)}$ that residents in Taiwan exposed to high levels of arsenic (cumulative exposure $>14.7 \mathrm{ppm}$-year or drinking artesian well water $>21 \mathrm{yr}$ ) and carrying the R-C-S haplotype (constituted by polymorphisms of paraoxonase genes PON1 Q192R, -108C/T and PON2 C311S) were associated with the incidence of electrocardiogram abnormality.

The individual susceptibility has been also discussed in the literature regarding the effects of non-chemical occupational factors. A recent review on noise-induced hearing loss (NIHL) ${ }^{8)}$ summarized the studies on the genetic factors that may influence one's susceptibility to NIHL; most of them were made on the polymorphisms of genes that are involved in oxidative stress such as the enzymes of glutathione metabolism, catalase, superoxide dismutase and paraoxonase, as well as heat shock proteins. A study by $\mathrm{Yu}$ et $a l .{ }^{9)}$ on the interactive effect of job stress and the genetic polymorphisms of beta-adrenergic receptor on hypertension revealed that the prevalence of hypertension was higher in individuals carrying Gly16 allele than in those carrying Arg16 allele among the high job stress group of workers. Thus, the health effects of job stress are varied according to the predisposing genetic factors. The study examined the relationships between coping skills, working hours, and psychological health among Japanese workers indicated that improving coping skills such as using instrumental support or positive reframing reduces the adverse health effects of long working hours ${ }^{10)}$. Interestingly, a non-randomized trial showed that a stress inoculation training program developed problem-solving skills and positive cognition, with a significant effect remaining one month after the intervention ${ }^{11)}$, suggesting that the susceptibility to occupational stress can be controlled by adequate interventions.

Regarding smoking and drinking, our research group reported their genotoxic effects in relation to genetic polymorphisms ${ }^{12-14)}$, using the cytokinesis-block micronucleus assay in peripheral blood lymphocytes, which is an established biomarker of genome instability. Ethanol is converted to acetaldehyde by alcohol dehydrogenase, cytochrome P4502E1 (CYP2E1) and catalase. This metabolite is then detoxified by aldehyde dehydrogenase 2 (ALDH2), a key enzyme in the elimination of acetaldehyde, via further oxidation to acetic acid. We investigated the effects of alcohol-drinking behavior and polymorphisms in two different genes (ALDH2 and CYP2E1) on the micronuclei (MN) frequency in healthy Japanese 
male workers ${ }^{12)}$. The study indicated that the ALDH2 variant (deficient type) was significantly associated with an increased MN frequency in habitual drinkers, while those with wild-type CYP2E1 showed a significantly increased MN frequency. Also, the study on the genetic polymorphisms of alcohol dehydrogenase-2 (ADH1B) and ALDH2 showed a significant trend for the mean MN frequency in habitual or moderate drinkers to increase as the numbers of the $* 1$ allele in ADH1B increased and the $* 2$ allele in ALDH2 increased ${ }^{13)}$. We also investigated the effects of smoking on MN frequencies in relation to five folate metabolic enzyme gene polymorphisms (MTHFR C677T and A1298C, MTR A2756G, MTRR A66G and TYMS 3'UTR) in 132 healthy Japanese male workers who were non-habitual drinkers ${ }^{14}$. In never- and former-smokers, no significant differences in $\mathrm{MN}$ frequencies were observed according to these folate metabolic enzyme gene polymorphisms. In current-smokers, however, subjects with the AA genotype for MTRR had a significantly higher MN frequency than the AG genotypes. The MN frequency was increased as the number of cigarettes smoked per day increased in subjects with the MTRR AA genotype. Thus, the MTRR AA genotype seems to act to increase the MN frequency resulting from cigarette smoking.

This special issue of Industrial Health, "Individual Susceptibility to Occupational Hazard", deals with the individual variability in the effects of various occupational factors including nine articles which refer to chemi$\mathrm{cal}^{15-18)}$, psychosocial ${ }^{19-21)}$, biological ${ }^{22,23)}$ and physical factors $^{24)}$. The articles regarding chemical factors include a systematic review by Julvez and Grandjean on neurodevelopmental toxicity ${ }^{15}$. The exposure to chemicals in early developmental stage is an important issue in occupational health, because the substantial vulnerability of the developing nervous system to low concentrations of neurotoxic chemicals should lead to a strengthened emphasis on protection of pregnant workers and women in general against substances that may cause harm to the fetus. Another review article by Kezic et al. ${ }^{16)}$ discuss the individual susceptibility to occupational contact dermatitis. They conclude that recent discoveries on genes involved in the skin barrier, inflammatory response and biotransformation of xenobiotics provide more insight in the individual susceptibility for occupational contact dermatitis, and that knowledge of the factors which predispose to this disease is useful for the application of preventive measures and for career guidance for apprentices and workers. Miura ${ }^{17)}$ presents a review on the individual susceptibility to cadmium toxicity, suggesting that if workers are exposed to industrial materials that have a inhibitory mechanism similar to that of $D L$-propargylglycine , an inhibitor of the cystathionine pathway (cystathionase inhibitor), free cadmium ions accumulate in the body due to the absence of metallothionein, resulting in serious renal dysfunction. In their original article, Zheng et al. ${ }^{18)}$ report the genetic polymorphisms of $\mathrm{N}$-acetyltransferase (NATs) are related to trichloroethylene - induced hypersensitivity dermatitis. They suggest that slow metabolic phenotype of NAT2 maybe one of risk factor for the dermatitis and combined slow acetylator phenotypes of NAT1 and NAT2 further increase such risk.

Three original articles regarding psychosocial factors are presented in this special issue. A survey on workers by Shimazu and Shaufeli ${ }^{19)}$ shows that workaholism is associated positively with psychological distress and physical complaints, and negatively with job and family satisfaction and job performance, whereas work engagement is related negatively to psychological distress and physical complaints and positively to job and family satisfaction and job performance, suggesting that workaholism and work engagement are two different kinds of concepts, which are negatively and positively related to well-being, respectively. Urakawa and Yokoyama ${ }^{20)}$ report that high Sense of Coherence (SOC) enables workers to cope with their job demand, which is a potent job stressor, indicating that SOC is an important factor determining the coping ability to job stress for both males and females. In addition, this paper mentions that male managerial employees may cope with their strong job stress because of high SOC whereas social support is significant for prevention of mental well-being of female workers from work-related stressors. Tei-Tominaga et al. ${ }^{21)}$ point out that depressive and anxious temperaments attenuate the influence of working hours and influence effort and rewards independently; while actual working hours have more impact on perceived high effort, understanding anxious and depressive temperaments have a significant role in stress self-management. Thus, these three studies suggest that individual factors prevent adverse health effects caused by psychosocial stressors at work; establishing adequate intervention strategies are necessary.

A review on the individual differences in vulnerability to sleep loss in the work environment is given by van Dongen and Belenky ${ }^{22)}$. They point out that methods for identifying workers at risk of sleep loss-related errors and accidents would be helpful to target fatigue countermeasure interventions although no reliable predictors of vulnerability to sleep loss have been identified. They mention that employment selection (discrimination) based on genetic predictors of predisposition to performance impairment is prohibited by the Genetic Information Nondiscrimination Act in the United States; selection or restriction processes and targeted interventions based on actual performance observations or tests are, at least in 
principle, legally acceptable, however. A study using human volunteers is conducted by Kubo et al. ${ }^{23)}$ to characterize the recovery pattern of sleep following successive night shifts. They indicate that sleep habits (bed time and variation of wake time) prior to the experiment are significantly related to the recovery patterns, rather than performance and alertness during the night shifts.

An experimental study by Kranjnak et al. ${ }^{24)}$ examines if metabolic syndrome alters vascular responses to vibration, using the animal model (obese Zucker rat). This is interest because overweight workers with metabolic syndrome are pre-disposed to developing peripheral vascular disorders; they also are at greater risk of developing vibration-induced white finger. The study indicates that vibration interferes with endothelial-mediated vasodilation, and that metabolic syndrome exacerbates these effects.

"Healthy Work Life in 21st Century Japan: National Occupational Research Strategies"25) in 1998 provided a framework to guide occupational health research in our country, showing three key areas, viz I. Research on issues related to working life and health that arise from changes in the occupational structure, II. Research on the human health effects of hazardous workplace factors, and III. Research on risk assessment and the management system for occupational health and safety, consisting of a total of 18 priority issues. "Individual differences in effects on health" is one of the 18 issues and placed in the second key area. In this framework, two research areas have been considered as important, i.e. (1) Design of innovate approaches to harmonize genetic studies and epidemiology, and (2) Research on the usability of genetic information to risk management and risk communication. The aim of this special issue is to contribute to the promotion of researches on this priority issue, providing recent knowledge regarding the individual susceptibility at work. The special issue also shows that predisposing factors related to the individual susceptibility are not only genetic ones such as polymorphisms. A wide variety of studies should constitute the research area of "Individual differences in effects on health".

A proposal of this special issue was submitted to the editorial committee in June 2008. After it was approved, myself and the following four editors of the journal have taken the editorship: Fumio Kobayashi, MD, DMSc (Aichi Medical University School of Medicine, Japan), Setsuo Maeda, DEng, DMSc (National Institute of Occupational Safety and Health (JNIOSH), Japan), Shinichi Sawada, DMSc (JNIOSH, Japan), and Masaya Takahashi, DMSc (JNIOSH, Japan). This special issue is indebted to collaborating efforts of all these editors.

\section{References}

1) Faustman EM, Omenm GS (2001) Risk assessment. In: Casarett and Doull's Toxicology, Klassen CD (Ed.), The Basic Science of Poisons, 6th Ed., 83-104, McGrawHill, New York.

2) Costa LG, Manzo L (1998) Biomarkers in occupational neurotoxicology. In: Occupational Neurotoxicology, Costa LG, Manzo L (Eds.), 75-100, CRC Press, Boca Raton.

3) Godderis L, Maertens N, de Gelder V, De Lamper A, De Ruyck K, Vernimmen M, Bulterys S, Moens G, Thierens H, Viaene MK (2009) Genetic susceptibility in solvent induced neurobehavioral effects. Neurotox Res 2009 Aug 22 (Epub ahead of print).

4) Zhao Y, Wang L, Shen HB, Wang ZX, Wei QY, Chen F (2007) Association between delta-aminolevulinic acid dehydratase (ALAD) polymorphism and blood lead levels: a meta-regression analysis. J Toxicol Environ Health A 70, 1986-94.

5) Horska A, Kazimirova A, Barancokova M, Wsolova L, Tulinska J, Dusinska M (2006) Genetic predisposition and health effect of occupational exposure to asbestos. Neuroendocrinol Lett 27 (Suppl 2), 100-3.

6) Yucesoy B, Johnson VJ, Kissling GE, Fluharty K, Kashon ML, Slaven J, Germolec D, Vallyathan V, Luster MI (2008) Genetic susceptibility to progressive massive fibrosis in coal miners. Euro Respir J 31, 1177-82.

7) Liao YT, Li WF, Chen CJ, Prineas RJ, Chen WJ, Zhang ZM, Sun CW, Wang SL (2009) Synergistic effect of polymorphisms of paraoxonase gene cluster and arsenic exposure on electrocardiogram abnormality. Toxicol Appl Pharmacol 239, 178-83.

8) Konings A, Van Laer L, Van Camp G (2009) Genetic studies on noise-induced hearing loss: a review. Ear Hear 2009 Feb 3 (Epub ahead of print).

9) Yu SF, Zhou WH, Jiang KY, Gu GZ, Wang S (2008) Job stress, gene polymorphism of beta2-AR, and prevalence of hypertension. Biomed Environ Sci 21, 239-46.

10) Otsuka Y, Sasaki T, Iwasaki K, Mori I (2009) Working hours, coping skills, and psychological health in Japanese daytime workers. Ind Health 47, 22-32.

11) Kawaharada M, Yoshioka E, Saijo Y, Fukui T, Ueno T, Kishi R (2009) The effects of a stress inoculation training program for civil servants in Japan: a pilot study of a non-randomized controlled trial. Ind Health 47, 173-82.

12) Ishikawa $H$, Miyatsu $Y$, Kurihara K, Yokoyama $K$ (2006) Gene-environmental interactions between alcohol-drinking behavior and ALDH2 and CYP2E1 polymorphisms and their impact on micronuclei frequency in human lymphocytes. Mutat Res 594, 1-9.

13) Ishikawa $H$, Ishikawa $T$, Yamamoto $H$, Fukao $A$, Yokoyama K (2007) Genotoxic effects of alcohol in human peripheral lymphocytes modulated by ADH1B and ALDH2 gene polymorphisms. Mutat Res 615, 
134-42.

14) Ishikawa $H$, Ishikawa $T$, Miyatsu $Y$, Kurihara $K$, Fukao A, Yokoyama K (2006) A polymorphism of the methionine synthase reductase gene increases chromosomal damage in peripheral lymphocytes in smokers. Mutat Res 599, 135-43.

15) Julvez J, Grandjean P (2009) Neurodevelopmental toxicity risks due to occupational exposure to industrial chemicals during pregnancy. Ind Health 47, 459-68.

16) Kezic S, Visser MJ, Verberk MM (2009) Individual susceptibility to occupational contact dermatitis. Ind Health 47, 469-78.

17) Miura N (2009) Individual susceptibility to cadmium toxicity and metallothionein gene polymorphisms: with references to current status of occupational cadmium exposure. Ind Health 47, 487-94.

18) Dai Y, Leng S, Li L, Niu Y, Huang H, Liu Q, Duan H, Cheng J, Liu Q, Zheng Y (2009) Effects of genetic polymorphisms of $\mathrm{N}$-acetyltransferase on trichloroethylene - induced hypersensitivity dermatitis among exposed workers. Ind Health 47, 479-86.

19) Shimazu A, Schaufeli WB (2009) Is workaholism good or bad for employee well-being? The distinctiveness of workaholism and work engagement among Japanese employees. Ind Health 47, 495-502.

20) Urakawa K, Yokoyama K (2009) Sense of Coherence (SOC) may reduce the effects of occupational stress on mental health status among Japanese factory workers. Ind Health 47, 503-508.

21) Tei-Tominaga M, Akiyama $T$, Miyake $Y$, Sakai $Y$ (2009) The relationship between temperament, job stress and overcommitment: a cross-sectional study using the TEMPS-A and a Scale of ERI. Ind Health 47, 509-17.

22) Van Dongen HPA, Belenky G (2009) Individual differences in vulnerability to sleep loss in the work environment. Ind Health 47, 518-26.

23) Kubo T, Takahashi M, Tachi N, Takeyama H, Ebara T, Inoue T, Takanishi T, Murasaki G, Itani T (2009) Characterizing recovery of sleep after four successive night shifts. Ind Health 47, 527-32.

24) Kranjnak K, Waugh S, Johnson C, Miller R, Kiedrowski M (2009) Vibration disrupts vascular function in a model of metabolic syndrome. Ind Health 47, 533-42.

25) Ministry of Labour and The Conference of Occupational Health Research Strategies in the 21st Century (1998) Healthy Work Life in 21st Century Japan: National Occupational Research Strategies, National Institute of Industrial Health, Tokyo.

Kazuhito YOKOYAMA, MD, DMSc

Juntendo University School of Medicine, Japan 